\title{
SEXY CERAMICS
}

Op 27 augustus is in Keramiekmuseum Princessehof Sexy Ceramics geopend. In deze tentoonstelling wordt aan de hand van historische en hedendaagse objecten uit Oost en West getoond dat er een duidelijke band is tussen erotiek en keramiek.

In Sexy Ceramics laten we zien hoe interessant en prachtig de erotische kunst kan zijn. De woorden erotiek en seks hebben vaak een vulgaire bijklank, maar de keramische werken die worden getoond zijn over het algemeen verre van ordinair. Erotiek hoort bij het leven; dit zie je terug in alle kunstvormen en in het bijzonder in de keramiek. De Canadese keramist Paul Mathieu heeft over dit onderwerp een boek geschreven met de toepasselijke naam Sex Pots: Eroticism in Ceramics waarin hij stelt dat: 'The relationship between clay as a material, ceramic as a practice, and sexuality itself are numerous. All imply touch and transformation, and touch is the dominant sense when it comes to working with plastic clay'. ${ }^{\prime}$ In de documentaire De Opvolger van Kakiemon zien we hoe een van de keramisten in de werkplaats zijn handen laat glijden door de fijne, witte, natte klei om zo de massa tot een vaas te vormen. Documentairemaker Suzanne Raes heeft deze scène zelf omschreven als 'kleiporno'. Ze laat de kijker zien hoe het werken met dit materiaal een sensuele lading heeft. Op internet zijn talloze vergelijkbare fragmenten te vinden waarin dit duidelijker wordt. Dit wordt beaamd door hedendaagse keramisten als Alexandra Engelfriet, Irene Vonck, Takeshi Yasuda en Satoru Hoshino. Laatstgenoemde staat bekend om zijn intieme relatie met klei. In zijn werk zie je zijn vingerafdrukken nog zitten (afb. I). De klei is op allerlei manier te vormen, door duwen, trekken en masseren. Dit verklaart wellicht de aantrekkingskracht van het materiaal.

Toeval of niet, hoe we de verschillende onderdelen van een vaas benoemen, is verbonden met het menselijk lichaam; zo heeft een vaas een buik, een hals, oren en een voet, en je kunt de huid aanraken. Een bekende keramische vorm in Zuidoost-Azië is de kendi ('kruik'). De kendi heeft vaak een tuit in de vorm van een borst, veelal beschouwd als een symbool voor de vruchtbaarheid (afb. 2). De kendi was zeer populair, zowel voor praktisch gebruik als voor rituele praktijken. Er kan uit het object gedronken worden door de kendi met één hand aan de hals boven het hoofd vast te houden en te kantelen zodat de vloeistof uit de tuit in de mondopening stroomt. Het is een hygiënische manier van drinken want de mond raakt de tuit niet aan. Een kendi kent zowel mannelijke als vrouwelijke vormen. De mannelijke vorm is hoekig en heeft een vierkante schouder, de vrouwelijke vorm heeft een ronder voorkomen. Wanneer

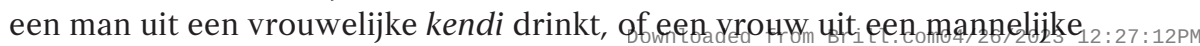


Afb. 1

Satoru Hoshino, Spiral with spring snow, steengoed, vinr. h. $21 \mathrm{~cm}, 61,5 \mathrm{~cm}$, $41 \mathrm{~cm}$, Japan, 2011, Keramiekmuseum Princessehof, MPH 2011-026. Foto: Johan van der Veer

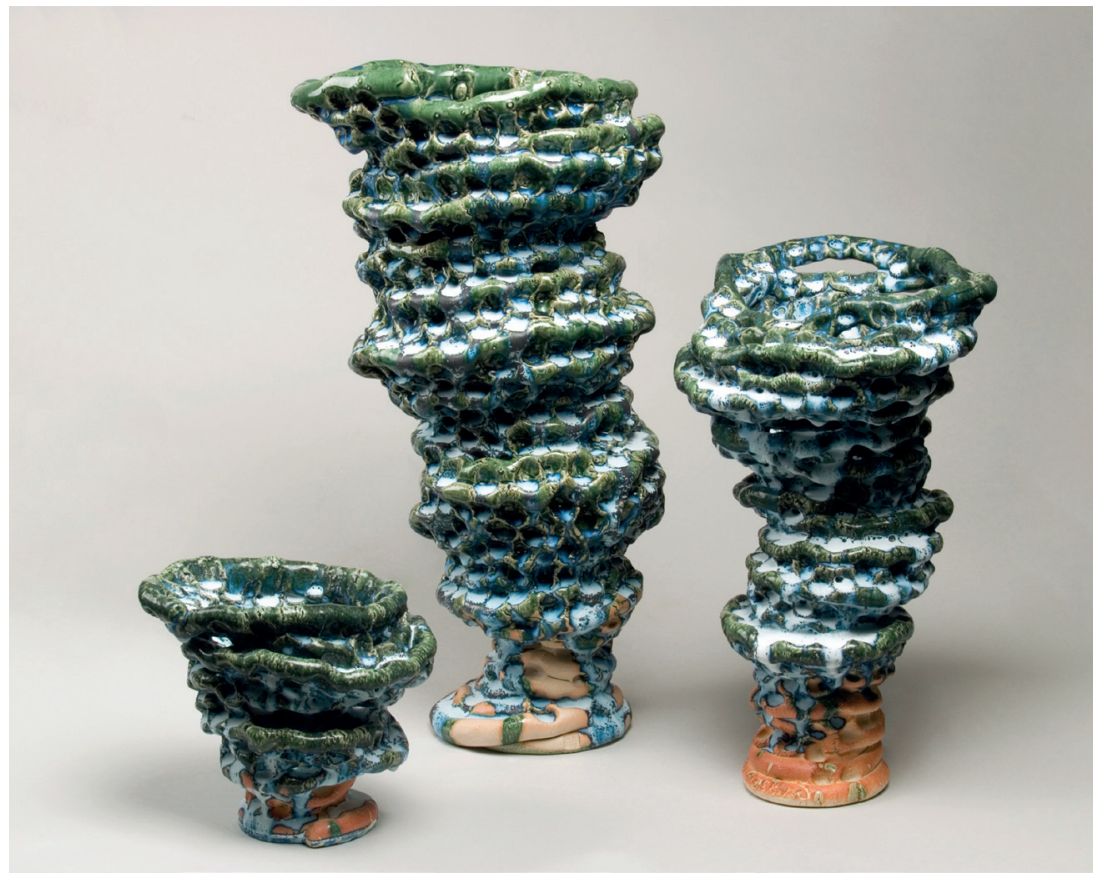

kendi, verwijst dit naar voortplanting. In hindoe rituelen is het schenken van water in iemands handen symbool van geven, in de vorm van een materiële gift, maar ook het geven van jezelf. In Indonesië is het een teken van toewijding als de bruid water uit een kendi in de hand van de bruidegom giet. Ze toont daarmee tevens respect aan de godin van de rijst, die op haar beurt symbool staat voor de vruchtbaarheid. ${ }^{2}$ Zo kan één object direct of indirect verschillende erotische associaties bevatten.

Afb. 2

Kendi, porselein,

h. $15.3 \mathrm{~cm}$,

China, 1700-1800,

Keramiekmuseum

Princessehof,

NO o1842. Bruikleen

Ottema-Kingma

Stichting. Foto:

Johan van der Veer

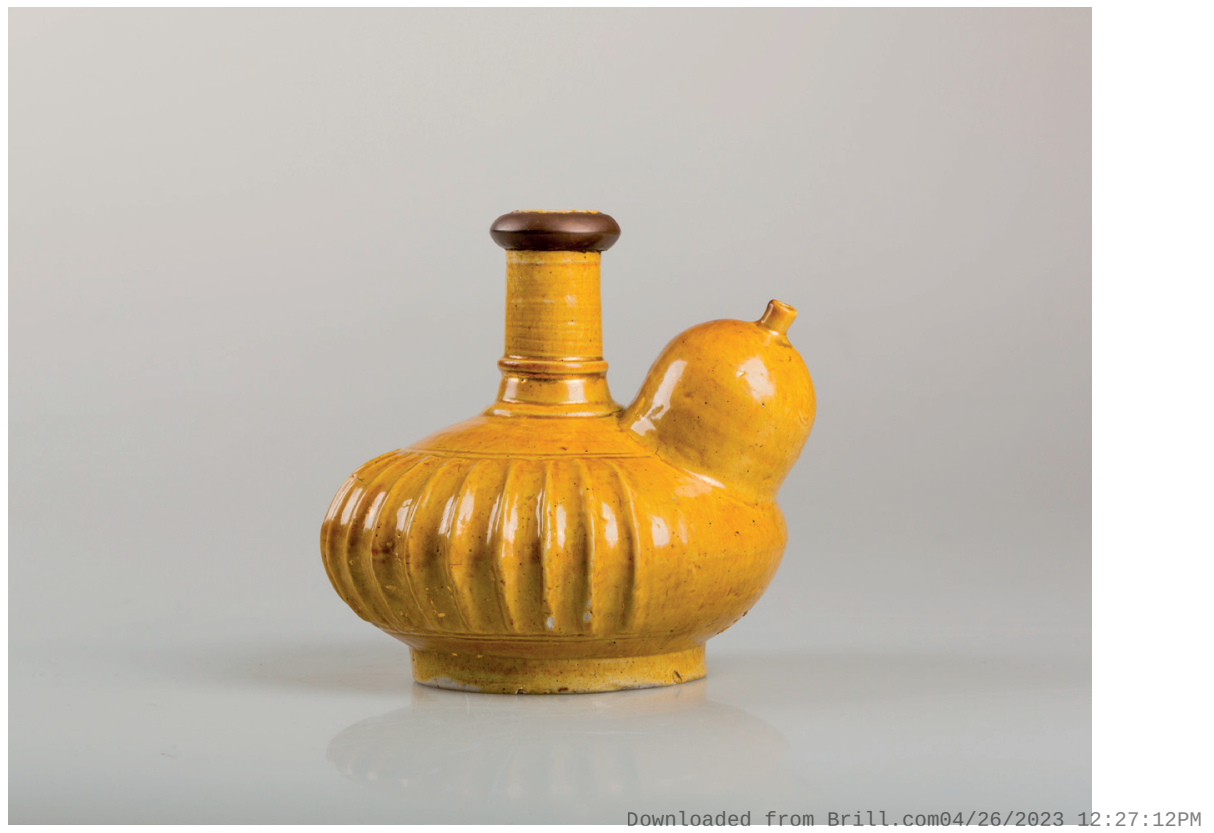



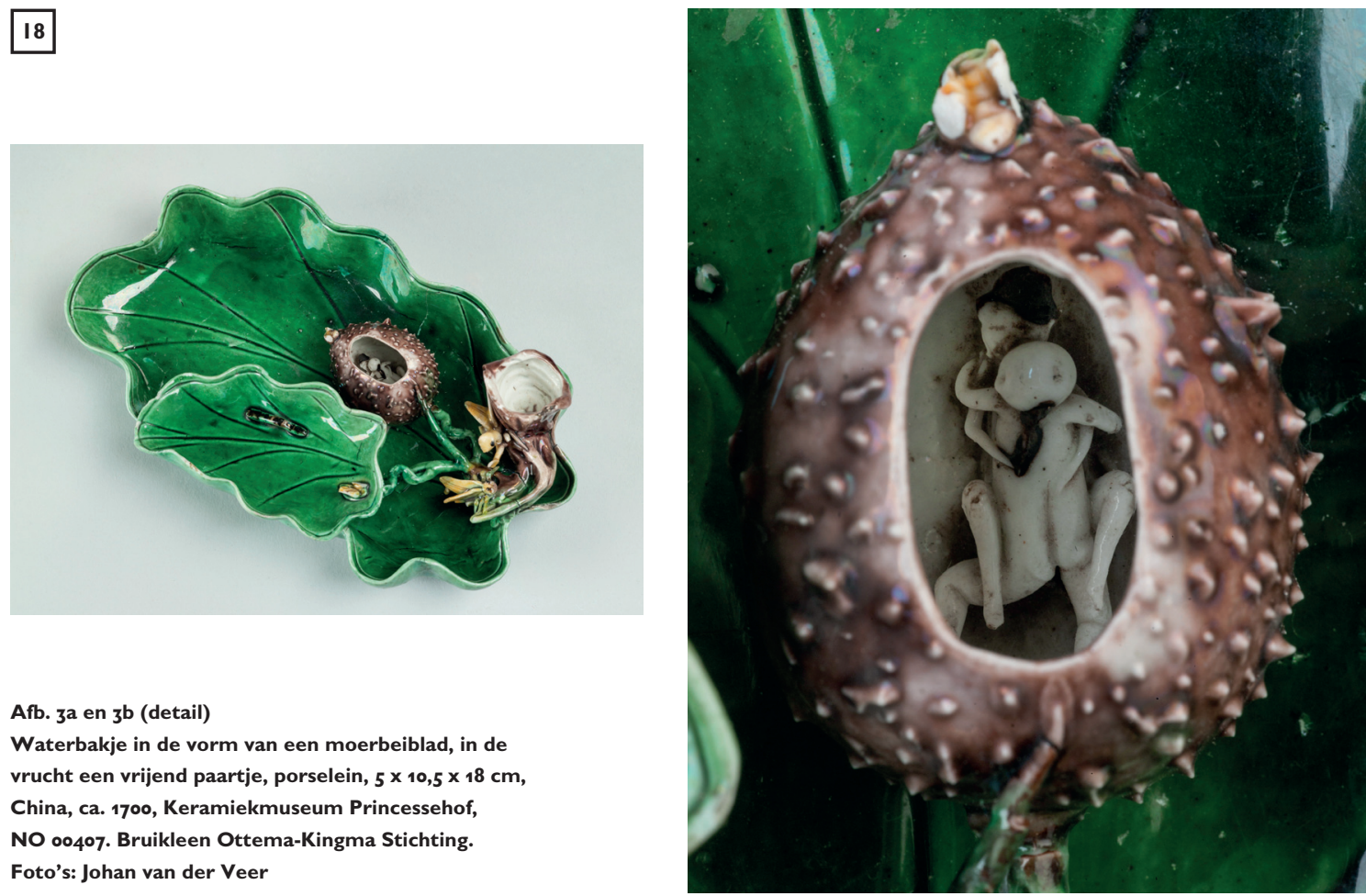

Afb. za en $3^{b}$ (detail)

Waterbakje in de vorm van een moerbeiblad, in de vrucht een vrijend paartje, porselein, $5 \times 10,5 \times 18 \mathrm{~cm}$, China, ca. 1700, Keramiekmuseum Princessehof, NO 00407. Bruikleen Ottema-Kingma Stichting. Foto's: Johan van der Veer

In de historische collectie van het Princessehof zijn weinig expliciet erotische objecten aanwezig. Toch is er rond I930 een bijzonder stuk aangekocht door oprichter Nanne Ottema bij antiquair A. van Messel in Amsterdam. Het betreft een penselenbakje uit de Kangxi-periode (r. I662-I722) in de vorm van het blad van een moerbeiboom (afb. 3a). Het porseleinen bakje is zeer verfijnd, zelfs de nerven van het blad zijn tot in precisie ingesneden. Zo op het eerste gezicht een prachtig object dat het bureau van een geleerde kan sieren. Als je echter beter kijkt, ontdek je een kleine verrassing die wellicht diende om tijdens de lange uren achter het bureau weer even wakker te worden, een ondeugend pleziertje tussendoor. In de vrucht zit namelijk iets verborgen: twee prachtig gevormde mensen in wit porselein die met elkaar de liefde bedrijven (afb. 3b). En wat blijkt, de vrouw heeft ook nog ingebonden voeten, wat bekend stond als het erotische symbool van de vrouw. In de tentoonstelling zijn meer van dit soort stiekeme pleziertjes te zien, zoals een $\mathrm{I}^{\mathrm{e}}$-eeuwse snuiffles met aan de voorzijde mooi geklede echtpaartjes en op de achterzijde diezelfde echtparen, maar dan naakt en in verschillende houdingen. Of bijvoorbeeld een $\mathrm{I}^{\mathrm{e}}$-eeuwse Chinese doos gedecoreerd in blauw-wit met bloemen en planten, maar aan de onderkant van het deksel is een vrijend stel afgebeeld. Ook deze vrouw heeft haar schoentjes nog aan. Gezien de verfijndheid van deze erotische objecten zullen ze niet zomaar door iemand gekocht zijn. Ze waren bestemd voor de goed bedeelde bovenlaag van de bevolking.

Een zeer bekend erotisch symbool in China is de ingebonden voet bij de vrouw. Rond de $\mathrm{IO}^{\mathrm{e}}$ eeuw werd met deze traditie begonnen. De

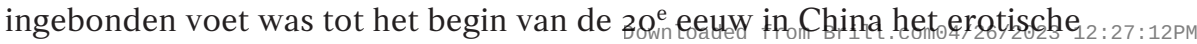




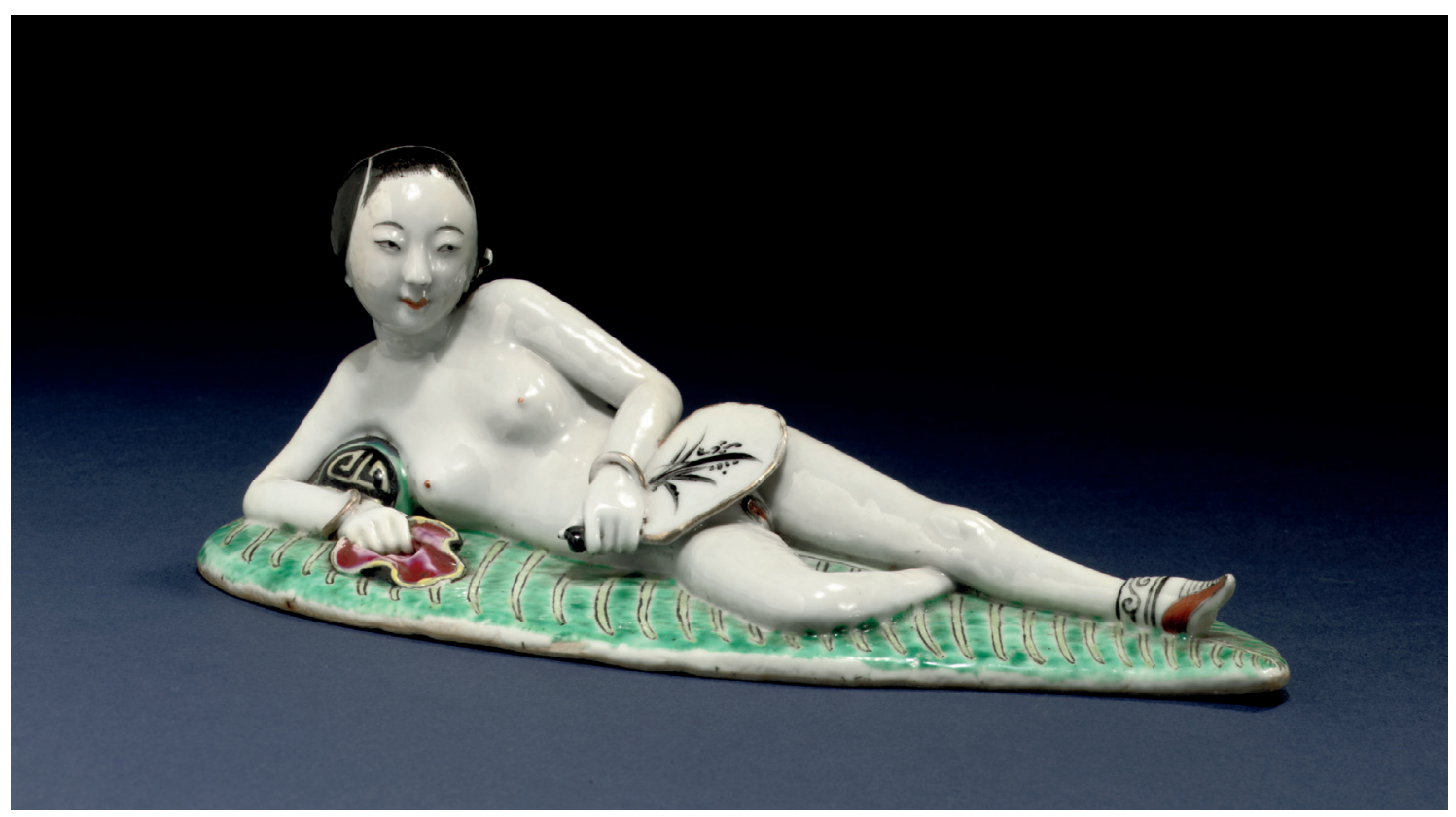

Afb. 4

Naakte vrouw met

waaier in haar

hand, porselein,

$19,8 \mathrm{~cm}$, China, eind

$19^{\mathrm{e}}$ eeuw. Collectie

Ferry Bertholet,

Amsterdam. Foto:

Michiel Elsevier

Stokmans symbool van de vrouw. De voet gold als een van de meest intieme delen van een vrouw, die alleen door haar zelf, haar moeder en haar man gezien mocht worden. ${ }^{3}$ In de Chinese niet-erotische kunst wordt dit lichaamsdeel dan ook vrij zelden afgebeeld. In de tentoonstelling zijn twee ${ }^{\mathrm{e}} \mathrm{e}^{\mathrm{e}}$-eeuwse borden te zien waarop de ingebonden voet van de vrouw wel zichtbaar is. Verder worden er enkele prachtig porseleinen beeldjes getoond van verleidelijke vrouwen uit de collectie Bertholet. Allemaal zijn ze naakt op één onderdeel na: de voet. Deze is verpakt in prachtige zijden stof, zoals mooi is te zien bij de dame liggend op een bananenblad (afb. 4). Juist door haar naaktheid wordt de blik getrokken naar de charmante voetjes. In het Westen is de symboliek van de voet minder sterk aan de erotiek verbonden, maar toch gold ook hier een zekere intimiteit voor dit lichaamsdeel. Zo zijn in de tentoonstelling $\mathrm{I}^{\mathrm{e}}$ en $\mathrm{I} 8^{\mathrm{e}}$ eeuw Delfts aardewerken schoentjes te zien die een populair huwelijkscadeau vormden. Ook Jean-Honoré Fragonard toonde in zijn olieverfschilderij Les Hasards Heureux de l'Escarpolette ('De vrolijke ongelukjes op de schommel'), gemaakt rond I767 en tegenwoordig onderdeel van de Wallace Collection, dat de voet van een meisje een enigszins ondeugende rol kan spelen. Het schilderij laat een meisje zien dat op een schommel zit. Als je beter kijkt zie je op de grond een jongen liggen die onder haar rokje kijkt. De dame is zich hier van bewust en schopt haar schoen uit in de richting van een Cupido waardoor haar enkel zichtbaar wordt.

In China is de erotische kunst nog altijd een ondergewaardeerd onderwerp. James Cahill, bekend van zijn onderzoek naar Chinese prenten en schilderingen, heeft hier uitgebreid onderzoek naar gedaan. Uit

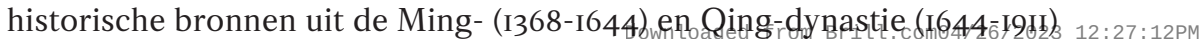




\section{Afb. 5}

Detail van bord

met scène van

twee vrouwen en

een schaal met

Boeddha's handfruit, porselein, d. $21 \mathrm{~cm}$,

China, 1750-1790,

Keramiekmuseum

Princessehof,

NO o0724. Bruikleen

Ottema-Kingma

Stichting. Foto:

Ruben van Vliet

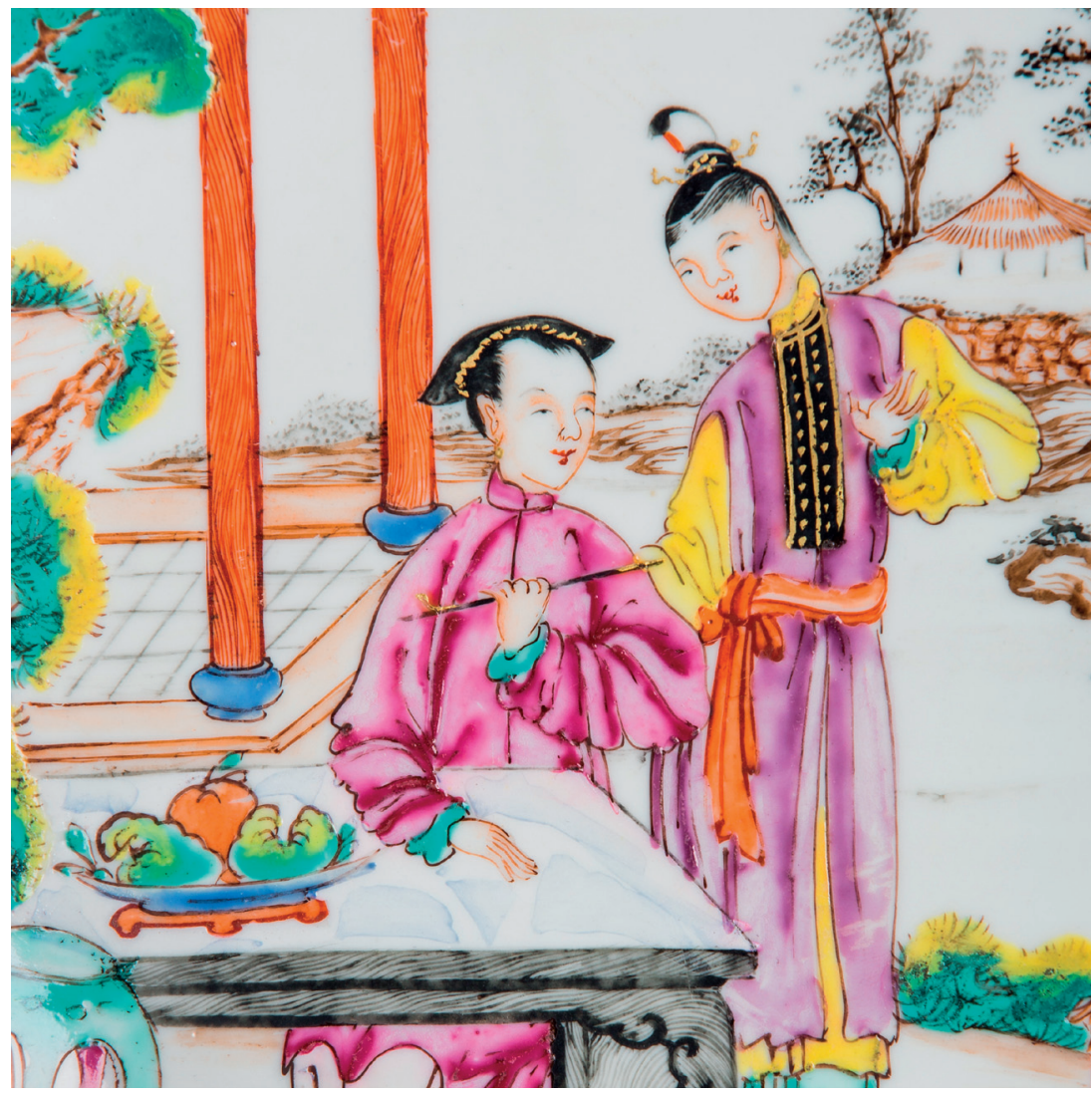

concludeerde hij dat erotische prenten door liefdesparen gebruikt werden om de lust op te wekken voor het vrijen en zo de seks gevarieerder te maken en intenser te beleven. Scènes waarbij een man en vrouw samen kijken naar prenten komen regelmatig voor op erotische schilderingen. ${ }^{4}$ Het is goed mogelijk dat de objecten met stiekeme voorstellingen een zelfde doel gediend hebben en in de privésfeer bewonderd werden. Het overgrote deel van deze erotische kunst bevindt zich waarschijnlijk nog altijd in verborgen collecties of wordt niet als zodanig beschreven. Een voorbeeld hiervan zijn afbeeldingen van mooie vrouwen. Chinese decoraties bevatten vaak symbolische verwijzingen waarbij alles draait om de juiste context. Cahill heeft met gedegen argumenten aangetoond dat in dit soort weergaves vaak veel erotische verwijzingen verstopt zitten. Dit maakt de afbeeldingen minder onschuldig dan je zo op het eerste gezicht zou denken. Zo symboliseert de mouw van de kleding van een vrouw 'de ingang naar de intieme delen van haar lichaam' wanneer zij haar arm omhooghoudt en daarmee zinspeelt op een seksuele uitnodiging. ${ }^{5}$ Een ander voorbeeld is een fruitschaal gevuld met Boeddha's hand (Lat. Citrus medica var. Sarcodactylis), ook wel vingercitroen of vingervormige sukadeboom genoemd, en veelvuldig gebruikt als offerande tijdens het Chinees Nieuwjaar, met daarnaast een aantrekkelijke vrouw (afb. 5). Het exotische fruit wordt door Cahill geïnterpreteerd als symbool van het vrouwelijke geslachtsdeel. ${ }^{6}$ Dit wordt nog verstrekt door de zoete geur die het fruit afgeeft. Het zijn deze subtiele verwijzingen die de afbeeldingen zo interessant maken. 
In de tentoonstelling Sexy Ceramics zijn nog veel meer erotische symbolen en suggestieve vormen te vinden. Daarom nodigen wij u graag uit een bezoek te brengen aan het Princessehof om te ontdekken hoe mooi de erotische kunst is en waarom dit juist in het keramiekmuseum zo op zijn plek is.

- Eline van den Berg is conservator Aziatische keramiek in Keramiekmuseum Princessehof. Ze heeft Chinese kunst en archeologie gestudeerd aan de Universiteit Leiden en SOAS (University of London) met als specialisatie Chinese keramiek.

- Sexy Ceramics 27 augustus t/m 9 juli 2017

Keramiekmuseum Princessehof, Leeuwarden

\section{LITERATUUR}

James Cahill, Pictures for Use and Pleasure: Vernacular Painting in High Qing China, Berkeley University of California Press, 2010.

Valerie Hansen, The Open Empire: A History of China to I60o, Norton, New York/ London, 2000.

Joo Ee Khoo, edited by Dawn F. Rooney, Kendi: Pouring Vessels in the University of Malaya Collection, Oxford University Press, Singapore, I99I.

Paul Mathieu, Sex Pots: Eroticism in Ceramics, Rutgers University Press, London, 2003.

\section{ELEKTRONISCHE BRONNEN}

http://jamescahill.info/illustrated-writings/chinese-erotic-painting/preface-andintroduction (laatst bezocht 4 augustus 20I6).

http://jamescahill.info/illustrated-writings/chinese-erotic-painting/8-theemperors-erotica-ii-the-qianlong-albums-master (laatst bezocht 4 augustus 20I6).

\section{F I L M}

Suzanne Raes (ed. Elja de Lange), De Opvolger van Kakiemon, Submarine, 2012. http://www.npo.nl/het-uur-van-de-wolf/28-09-2013/NPS_I232583 (laatst bezocht 25 september 20I6).

\section{NOTEN}

I Mathieu 2003: 13.

2 Khoo I99I: 23-27.

3 Hansen 2000: 288.

$4 \mathrm{http}$ ///jamescahill.info/illustrated-writings/chinese-erotic-painting/preface-andintroduction

5 Cahill 2010: 156.

$6 \mathrm{http} / / /$ jamescahill.info/illustrated-writings/chinese-erotic-painting/8-theemperors-erotica-ii-the-qianlong-albums-master 


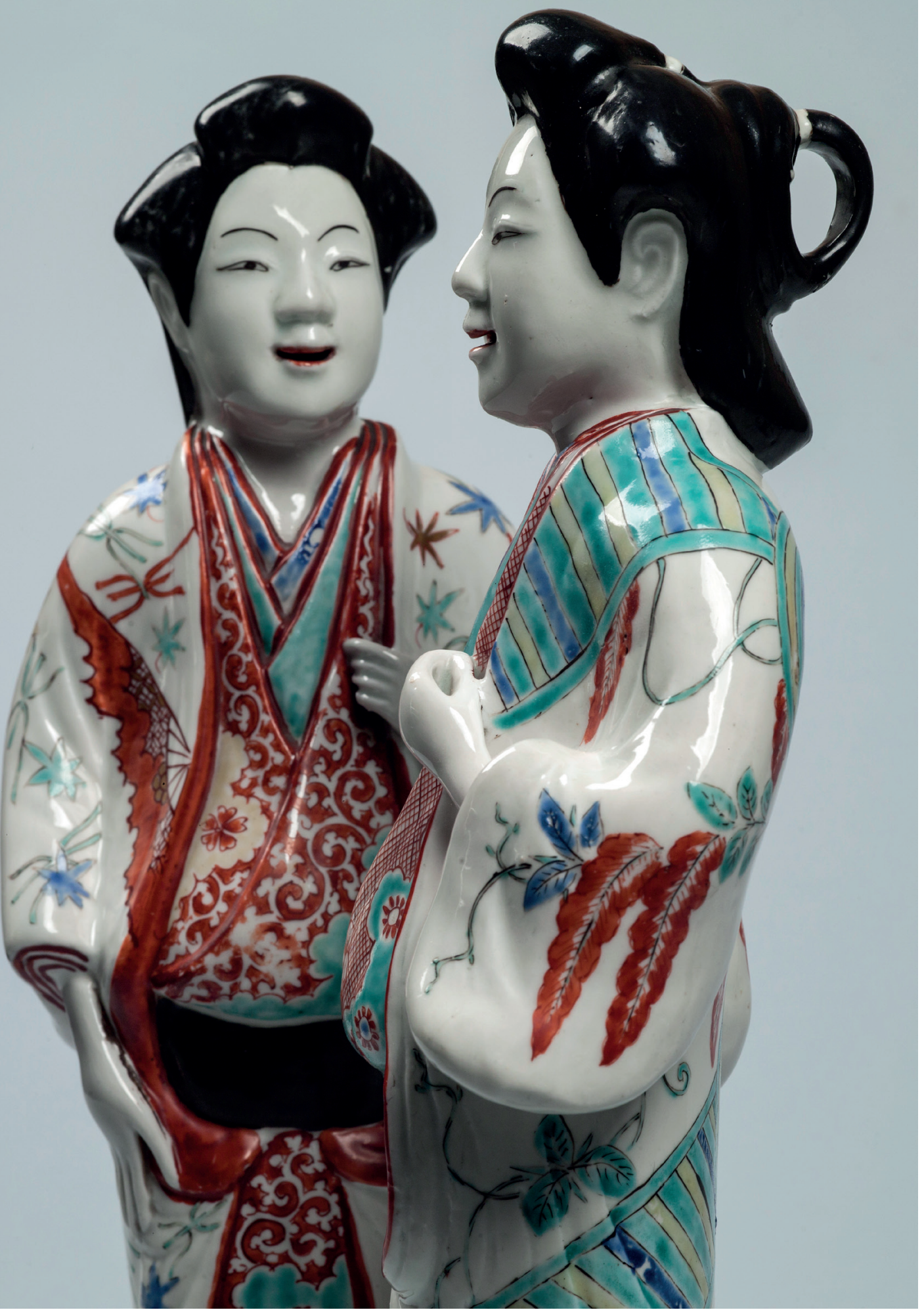

